\title{
Space Activities in Armenia: past, present and future
}

\author{
A. M. Mickaelian*and G. A. Mikayelyan ${ }^{\dagger}$ \\ NAS RA Byurakan Astrophysical Observatory (BAO), Byurakan 0213, Aragatzotn Province, Armenia
}

\begin{abstract}
A review about Space related activities in Armenia is given, particularly in the Byurakan Astrophysical Observatory (BAO, Armenia), including the first Space Astronomy projects by Grigor Gurzadian in 1960s-1970s (Orion and Orion-2 UV observatories), research projects with USA (NASA) and European (ESA) Space observatories (IRAS, ROSAT, Hubble, Spitzer, WISE, etc.) by BAO scientists, Armenian participation in International Virtual Observatory Alliance (IVOA), International Planetary Data Alliance (IPDA), and UN Committee on the Peaceful Users of the Outer Space (COPUOS), "Roscosmos" station in Byurakan established in 2014 for monitoring of Space debris, Armenian participation in NASA Space Apps Hackathons, Armenian participation in the European H2020 project, including the Space field, organization of Space related meetings and schools in Byurakan, etc. Armenia with its astronomical and other related background has great potential in establishing collaborations and promoting Space Sciences and Space Technologies.
\end{abstract}

Keywords: Space, Space observatories, Virtual Observatories, COPUOS, NASA, H2020 Space

\section{Introduction}

At present Armenia is a small country with limited economy (by area it is on the $143^{r d}$ position in the world, by population it is on the $134^{\text {th }}$ position and by budget it is on the $130^{\text {th }}$ position), however with a high level of science and technologies. Though Space activities are mainly carried out by big countries (like USA - NASA, Japan - JAXA) or by a group of countries (e. g. 22 European countries European Space Agency, ESA), Armenia has been and is involved in many Space related projects and collaborations, including Space Astronomy research projects by the Byurakan Astrophysical Observatory (BAO), Space Astronomy instrument making by BAO and Garni Space Astronomy Institute, participation in international space-related organizations, organization of international meetings and schools, etc.

Armenia with its astronomical and other related background has great potential in establishing collaborations and promoting Space Sciences and Space Technologies. In this article we give an overview of past, present and possible future activities developed in Armenia related to Space.

\section{Space Astronomy and Space related science at BAO in 1960s-1980s}

Grigor Gurzadyan (1922-2014) was the pioneer of Space Astronomy in Armenia and one of the pioneers in the USSR. In 1960s, using ballistic rockets R-5, he directed the UV and X-ray observations of the Sun and stars (the first launch was on February 15, 1961 from Kapustin-Yar base). His paper "A Powerful X-ray Flare on the Sun", published in Communications of Armenian SSR Academy of Sciences in 1966 is among the earliest papers on Space Astronomy. Then Gurzadyan moved to design Space orbital observatories; ultraviolet (UV) Orions were the most famous ones. In April, 1971 the first space station Salyut 1 carried Orion 1 onto the orbit, the first Space telescope with an objective prism. But the highlight was Orion 2, which was operated onboard the spacecraft Soyuz 13 in December, 1973. Here are the comparative specifications of Orion 1 and Orion 2 (Table 1).

*aregmick@yahoo.com, Corresponding author

${ }^{\dagger}$ gormick@mail.ru 


\begin{tabular}{|c|c|c|}
\hline Technical parameters & Orion 1 & Orion 2 \\
\hline Optical system & Mersenne & $\begin{array}{l}\text { meniscus, Cassegrain } \\
\text { Maksutov) system }\end{array}$ \\
\hline Spectrograph & Wadsworth & $\begin{array}{l}\text { objective prism; } 2 \text { additional } \\
\text { sidereal spectrographs }\end{array}$ \\
\hline Diameter of primary mirror & $280 \mathrm{~mm}$ & $300 \mathrm{~mm}$ \\
\hline Focal length & $1400 \mathrm{~mm}$ & $1000 \mathrm{~mm}$ \\
\hline Field of view & & $5^{\circ}$ \\
\hline Spectral range & $2000-3800 \AA$ & \\
\hline Spectral resolution & $5 \AA$ at $2600 \AA$ & $8-29 \AA$ at $2000-3000 \AA$ \\
\hline Film & $\begin{array}{l}\text { UFSh } 4 \text {, width } 16 \mathrm{~mm} \text {, range } \\
\text { sensitivity: } 4000-2500 \AA \text {, res- } \\
\text { olution better } 130 \text { lines } / \mathrm{mm}\end{array}$ & $\begin{array}{l}\text { KODAK 103UV, diameter: } \\
110 \mathrm{~mm}\end{array}$ \\
\hline Cartridge capacity & $12 \mathrm{~m}$ & \\
\hline Stabilization & $\begin{array}{l}\text { two-stage, inertial; first stage: } \\
\text { three-axis inertial stabiliza- } \\
\text { tion of station Salyut } 1\end{array}$ & $\begin{array}{l}\text { 2-star sensor sets: each con- } \\
\text { taining a two-coordinate star } \\
\text { sensor coaxial to telescope and } \\
\text { one-coordinate one, in } 45^{\circ} \text { to } \\
\text { telescope axis }\end{array}$ \\
\hline Fine guidance & $\begin{array}{l}\text { via a star with accuracy } 15 \\
\text { arcsec on each axis }\end{array}$ & $\begin{array}{l}\text { 3-axes guidance system accu- } \\
\text { racy: better than } 5 \text { arcsec } \\
\text { on two cross-sectional axes of } \\
\text { telescope (via star A), and } \\
\text { better than } 30 \text { arcsec at opti- } \\
\text { cal axis (star B) }\end{array}$ \\
\hline Star sensor & $\begin{array}{l}\text { of semi-disk (diameter of in- } \\
\text { put: } 70 \mathrm{~mm} \text {; focal length: } 450 \\
\text { mm), limiting stellar magni- } \\
\text { tude } 5^{m}\end{array}$ & $\begin{array}{l}\text { input apertures: } 80 \text { and } 60 \\
\text { mm; focal lengths: } 500 \text { and } \\
240 \mathrm{~mm} \text {; limiting stellar mag- } \\
\text { nitudes: } 3.5^{\mathrm{m}} \text { and } 3.0^{\mathrm{m}}\end{array}$ \\
\hline Mass & $170 \mathrm{~kg}$ & $240 \mathrm{~kg}$ (telescope $205 \mathrm{~kg}$ ) \\
\hline $\begin{array}{l}\text { Mass returned to Earth (car- } \\
\text { tridges) }\end{array}$ & & $4.3 \mathrm{~kg}$ \\
\hline Installation onboard & Salyut 1 & Soyuz 13 \\
\hline Observer cosmonaut & Viktor Patsaev & Valentin Lebedev \\
\hline Operational & June 1971 & Dec 1973 \\
\hline
\end{tabular}

Spectra of thousands of stars to $13^{\text {th }}$ stellar magnitude, the first satellite UV spectrogram of a planetary nebula were obtained revealing spectral lines of aluminum and titanium - elements not previously observed in planetary nebulae, two-photon emission from nebula was directed for the first time. For comparison, the US Skylab's UV telescope, which was on the orbit at the same time, could only observe stars down to $7.5^{\text {th }}$ magnitude. The obtained results were published in the most important astronomical journals, including 3 articles in "Nature" (Gurzadyan 1974, Gurzadyan \& Ohanesyan 1972, Gurzadyan \& Rustambekova 1975).

In the Byurakan Astrophysical Observatory (BAO), the Space Astronomy Research Department was operating in 1964-1968; then The Space Research branch was established and was operating in 1968-1973; later Space Astronomical Laboratory was opened in Garni and was operating in 19731978, the Extra-Atmospheric Astronomical Laboratory was operating in Byurakan in 1978-1992, and the Garni Institute of Space Astronomy headed by G. Gurzadyan was operating in 1992-2004. In 19671973 Gurzadyan headed BAO branch of space researches, in 1973-1978 he headed Garni Astronomy Laboratory, in 1978-1992 he was the Head of Extra-atmospheric Astronomy Laboratory of BAO, in 1992-2004 he was the Head of Garni Space Astronomy Institute. Since 1979 he established and was the Head of the Chair of Space Instrument-Making of Yerevan Polytechnic Institute as well. 

2002).

Gurzadyan published books related to Space flights and Space dynamics (Gurzadyan 1992, 1996,

Special Schools for Soviet astronauts (pre-flight training) were organized in BAO and in Garni in 1960s-1990s, where almost 40 future astronauts had obtained astronomical knowledge.
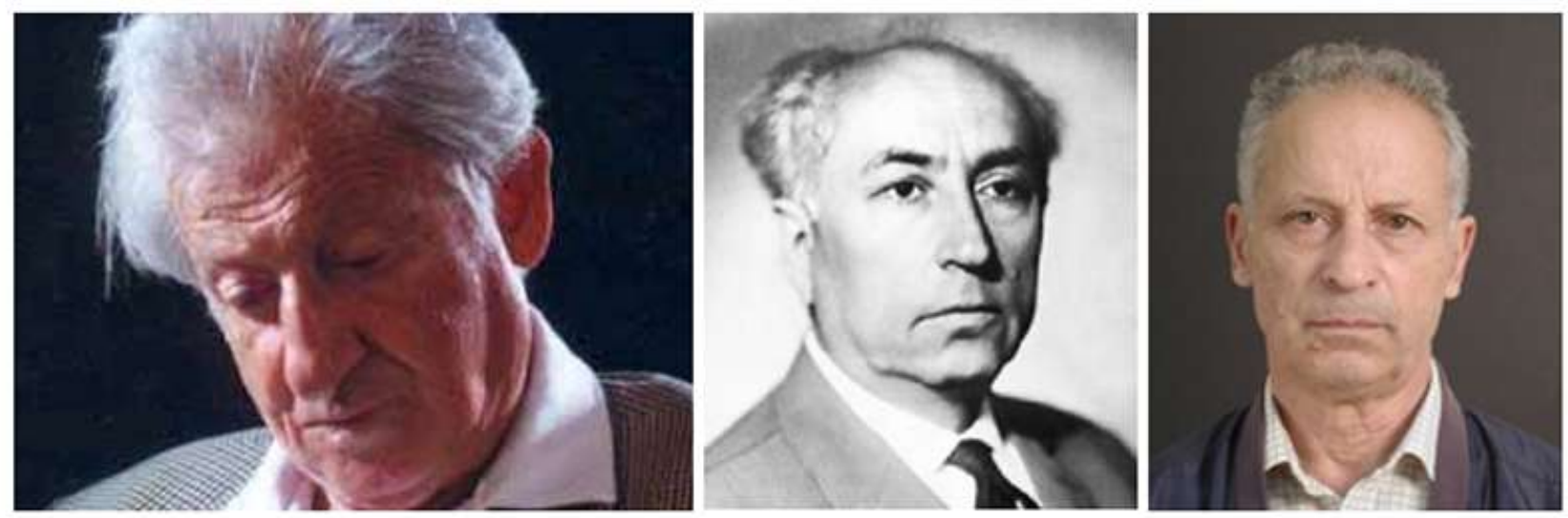

Grigor Gurzadyan, Norayr Sisakyan and Hrant Tovmassian

BAO researchers were engaged in other Soviet Space projects as well. Hrant Tovmassian (b. 1929) worked on the Space ultraviolet telescope Astron (Crimean Astrophysical Observatory; Boyarchuk et al. (1984)). Tovmassian's team made the guiding system. An offset guidance was proposed, which was made by the relatively bright star located nearby to the observed object on sky. It was made at the Granit Special Construction Bureau (SCB). The head of the project and the manufacturing was Marat Krmoyan. The telescope was launched to the orbit in1984.

Later on, Tovmassian initiated the project of the Space Ultraviolet Telescope Glazar for study of the far UV emission of OB type stars in stellar associations. The space telescope Glazar was projected and constructed in the Granit SCB in Garni. The diameter of the telescope mirror was 40 $\mathrm{cm}$. The Ritchey-Cretien optical system provided $1.3 \mathrm{deg}$ field of view. Observations were made at 1640A wavelength. The used optic-electronic detector transferred 1640A image of the observed field to a visual light, magnified it, and photographed at the ordinary film. The high-quality Kodak films were provided by the Geneva observatory (Switzerland). The telescope was launched to the orbit and attached to the Mir Space Station in 1987 (Tovmassian et al. 1988). Observations have been carried out by cosmonauts by commands from the center of the space communications at Energia near Moscow. Cosmonauts brought to the Earth the exposed films upon their return from the orbit. Usually the exposed films remain at the orbit for about one year. A number of scientific results were obtained, including the study of OB associations, discovery of dust envelopes around some distant B type stars, etc. In 1990, the Space Ultraviolet Telescope Glazar-2 was constructed and launched to the orbit and attached to the Mir Space Station. It differed from the first Glazar by higher sensitivity achieved by using the better ultraviolet filter. However, it did not work due to problems after the crash of the Soviet Union.

In 1990 at the Granit SCB we started the the projection and construction of the fully reflecting $1 \mathrm{~m}$ Astrophysical Schmidt Orbital Telescope (ASchOT) (Tovmassian et al. 1991). It was planned to perform an image and a spectral sky survey at 1500A. However, in the result of the collapse of the Soviet Union, the works on manufacturing the ASchOT were ceased.

Academician Norayr Sisakyan (1907-1966) was one of the founders of Space Biology and Space Medicine (Space Biomedicine). Sisiakyan was the Vice-President of the International Academy of Astronautics. For some new directions of biochemistry, we owe Sisakyan, who was more interested in cosmic biology. The scientist was convinced that the universe needed to look for life and organism, without doubt that there should be microorganisms at all. Thus, the scientific basis was based on the development of gravitational biology, the study of dimension and, as a consequence, the scientific principles of selection and preparation of cosmonauts, as well as the environmental, astronauts' survival and security issues. He did not doubt that Gagarin's flight would succeed, and he thought modestly 
that he had his scientific contribution to that success.

Telecommunication systems of Venus landing module were designed in NAS RA institutions, namely Institute of Radiophysics and Electronics (led by Radik Martirosyan), and experiments on microbes were developed on Soviet spacecrafts (led by Evrik Afrikyan).

\section{Space Astronomy and Space related science at BAO in 2000s-2010s}

A number of astrophysical research projects were carried out by BAO scientists with USA (NASA) and European (ESA) Space observatories. Some of the BAO scientists participated in American and European space astronomy programs, in particular Artashes Petrosian participated in the Hubble Space Telescope (HST) programs (Hayes et al. 2005, Kunth et al. 2010, Mas-Hesse et al. 2009) in collaboration with STScI in Baltimore, USA, and Areg Mickaelian's observational project on study of high-luminosity IR galaxies and IR excess galactic stars were carried out on IR Spitzer Space Telescope (SST) in collaboration with Cornell University (Ithaca, N.Y.) team (Hovhannisyan et al. 2009, Sargsyan et al. 2008). Mickaelian's Astronomical Surveys research department at BAO extensively uses space multiwavelength data for astrophysical research. Most important space telescopes that are used for multiwavelength analysis are IRAS, ROSAT, HST, SST, WISE, Herschel, etc.

In addition, the Digitized First Byurakan Survey (Markarian's Survey), the project of digitization of astronomical plates (Massaro et al. 2008, Mickaelian et al. 2007) was carried out due to collaborations with NASA and other several international organizations in 2002-2007. This survey and its digitized version are included in UNESCO's "Memory of the World" Documentary Heritage International Register.

NAS RA Byurakan Astrophysical Observatory has signed a contract with the Russian Space Agency "Roscosmos" in 2014, according to which monitoring of space artificial fragments (space debris) is carried out in Byurakan. Every year, some 200 observing nights are being used for some 400,000 measurements and some 600,000 orbits for artificial satellites are being recovered. There is a team of 8 BAO observers that support the observations. BAO Applied Astronomy Department is in charge for this project and Haik Harutyunian is the PI from the Armenian part.

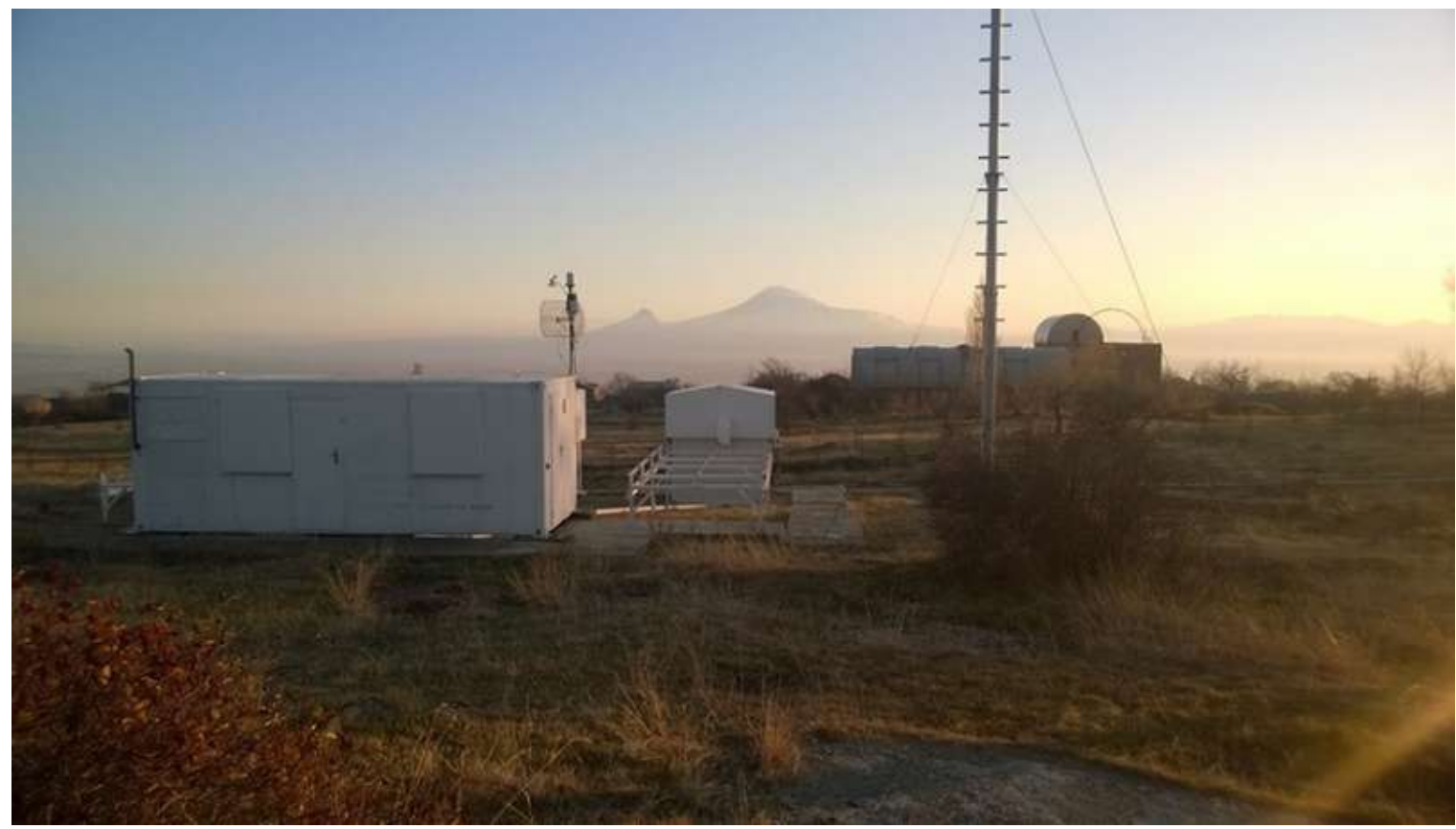

Applied Astronomy Department in Byurakan Astrophysical Observatory (BAO), Armenia, where joint project with Russians on monitoring of cosmic junk is being implemented.

In 2005, based on the Digitized First Byurakan Survey (DFBS or Markarian Survey), Areg Mickaelian created the Armenian Virtual Observatory (ArVO) project (Mickaelian 2006, 2007, Mickaelian et al. 2006), which joined the International Virtual Observatory Alliance (IVOA) in the 
same year. Virtual observatories use all data accumulated in astronomy, from both ground-based and Space telescopes, by all observational methods, at all wavelength ranges and in all epochs, which gives a huge advantage in sense of overall and complete studies compared to individual observations and studies. Mickaelian is IVOA Executive Committee member since 2005. Later on, in 2013, Armenia joined International Planetary Data Alliance (IPDA) as an associate member and Mickaelian became IPDA Steering Committee member. IPDA unifies space agencies of most important countries and communities (US National Aeronautics and Space Administration (NASA), European Space Agency (ESA), Japan Aerospace Exploration Agency (JAXA), China National Space Administration, Indian Space Research Organisation (ISRO), UK Space Agency (UKSA), German Aerospace Center Deutsches Zentrum für Luft- und Raumfahrt e.V. (DLR), French National Centre for Space Studies Centre National d'Études Spatiales (CNES), Italian Space Agency - Agenzia Spaziale Italiana (ASI), Russian Space Research Institute - Институт Космических Исследований (ИКИ), United Arab Emirates Space Agency and Armenia is represented by the Armenian Astronomical Society, ArAS). IPDA creates database for all planetary data (Sarkissian et al. 2016) and the DFBS project has contributed in it by data related to known asteroids and by search for new asteroids (Berthier et al. 2009, Mickaelian et al. 2019, Sarkissian et al. 2012).

\section{Organization of Space related meetings and schools in Byurakan}

In May 1964 (Tovmassian 1965) and Sep 1971 (Sagan 1973) conferences on extraterrestrial civilizations were held in Byurakan. The meeting of 1971 was the First international symposium on the problem of Extraterrestrial Civilizations and Communication with them (CETI). Many prominent scientists, including astronomers, physicists, chemists, biologists, philosophers, and specialists of other related fields participated in the symposium. 32 Soviet and 19 American scientists, as well as representatives from UK, Hungary, and Czechoslovakia participated in the works of the symposium, including the 3 Nobel Prize Winners: biologist F. Crick (UK) and physicists F. W. Dyson and C. Towns (USA). Prominent scientists F. Drake, T. Gold, C. E. Sagan, D. Heeschen, K. Kellermann (USA), F. Morrison (UK) and others also took part in the symposium. Many aspects of the problem of extraterrestrial intelligence were discussed at the ten scientific sessions of the symposium. Questions of plurality of planetary systems in the Universe, origin of life on the Earth and its possibility on other cosmic objects, rise and evolution of intelligent life, rise and development of technological civilization, problems of search for signals of extraterrestrial civilizations and traces of astroengineer activity, problems of establishment of communication with extraterrestrial intelligence, as well as their possible consequences were discussed in details.

A Conference for Young Astronomers was held in Nov 2011 (Mickaelian et al. 2012): 50 years of Cosmic Era: Real and Virtual Studies of the Sky. This was a Conference of young scientists from FSU countries, dedicated to the 50th anniversary of Yuri Gagarin flight to the Space. The main goal of the Conference was to gather young scientists from FSU countries to familiarize them with the latest developments of Astrophysics and Space Physics, including the using of the latest technology and techniques. Within three days for the young scientists were organized lectures and practical exercises on various areas of Astrophysics and Space Research, as well as them was provided the opportunity to present their works.

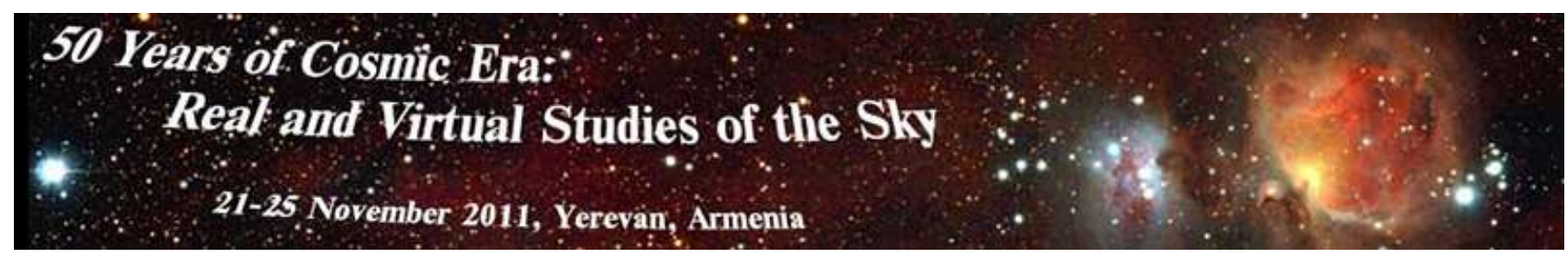

"Relation of Astronomy to other Sciences, Culture and Society" (RASCS, Harutyunian et al. (2015)) meeting was devoted to the role of astronomy in science, culture and other fields of human activity and development of these fields due to the knowledge obtained from the Universe. In 
modern era, astronomy is probably the field of science, which plays a leading role in the formation and development of interdisciplinary sciences. The meeting was aimed at the development of problems of interdisciplinary sciences in Armenia and preparation of a basis for further possible collaborations by means of presentations of available modern knowledge in various areas by experts from different professions and by joint discussions. Particularly, talks on life in the Universe, extraterrestrial intelligence, space flights, space hazards and space ecology were presented.

Orion-Byurakan school for young astronauts was organized jointly with Roscosmos and was held both in BAO and in Physics and Mathematics specialized school after A. Shahinyan (Yerevan State University) in 2017 for students mainly from Russia, and Armenian students joined as well. But the main initiative to activate Space Sciences and Technologies in Armenia and to prepare corresponding staff was the Regional Summer School on Space Sciences and Technologies held on 2-6 Sep 2019 in Byurakan (https://www.bao.am/meetings/meetings/SST/). It aimed at attracting beginner astronomers and related MSc and PhD students to the field of scientific research, teaching the principles of scientific work. Thanks to these, BAO plays a leading role in this region and offers opportunities for young people in the region to participate in high-level lectures and practical courses as there are not many opportunities for participating in European and American schools. Students in the region also have a wide range of opportunities to communicate, to make new acquaintances, which is very useful for their further advancement. Experts from ESA, LATMOS, "Roskosmos" and other important organizations were invited as lecturers. Several tutorials were also given.

IAU SOUTH WEST AND CENTRAL ASIAN REGIONAL OFFICE OF ASTRONOMY FOR DEVELOPMENT

\section{REGIONAL SUMMER SCHOOL ON SPACE SCIENCES AND TECHNOLOGIES}

2-6 September 2019, Byurakan, Armenia

\section{Armenian participation in Space related international organizations}

Armenia has joined the international Committee on Space Research (COSPAR), established by ICSU in 1958. Ashot Chilingaryan (Alikhanyan National Laboratory, ANL) is the Representative from Armenia. Among COSPAR's objectives are the promotion of scientific research in space on an international level, with emphasis on the free exchange of results, information, and opinions, and providing a forum, open to all scientists, for the discussion of problems that may affect space research. These objectives are achieved through the organization of symposia, publication, and other means. COSPAR has created a number of research programs on different topics, a few in cooperation with other scientific Unions.

Armenia is a member of the United Nations Office for Outer Space Affairs (UNOOSA). It works to promote international cooperation in the peaceful use and exploration of space, and in the utilization of space science and technology for sustainable economic and social development. The Office assists any UN Member States to establish legal and regulatory frameworks to govern space activities and strengthens the capacity of developing countries to use space science technology and applications for development by helping to integrate space capabilities into national development programs. UNOOSA is the UN office responsible for promoting international cooperation in the peaceful uses of outer space. UNOOSA serves as the secretariat for the General Assembly's only committee dealing exclusively with international cooperation in the peaceful uses of outer space: United Nations Committee on the Peaceful Uses of Outer Space (COPUOS, 87 member states), where Armenia became a member in 2014. The Armenian Space Agency (ArSA) has been formally created, which was an interdepartmental commission under the authority of the Ministry of Transport, Communication and Information Technologies. The current main objective of the Armenian Space Agency is having an Armenian own satellite. 
Armenia joined EC Horizon 2020 (H2020) project as an associate member in 2016. H2020 has 25 fields, including the Space. Areg Mickaelian and Aram Saharian are H2020 Space Program Committee (PC) members from Armenia, and Gor Mikayelyan and Hripsime Mkrtchyan are National Contact Points (NCPs). Armenian H2020 activities include many areas (http://h2020.sci.am/). Armenian scientists participated in H2020 COST Action TD1403 BigSkyEarth (Big Data Era in Sky and Earth Observation) and participate in H2020 COST Action CA18104 MW-Gaia (Revealing the Milky Way with Gaia). Areg Mickaelian was/is Management Committee (MC) member in both projects. A number of conferences and training schools were organized during 2015-2019.

\section{Armenian Space related current activities and legislative steps}

"The Space" sector has been included in the list of priority directions in the framework of interstate agreement between Armenia and Russia. The Governments of the Republic of Armenia and India have signed a Memorandum of Understanding on Peaceful Uses of Outer Space in 2017.

RA Security Council has been involved in Space Security field since 2018; "The Space development will lead the country towards more ensured security, furthermore it will encourage the growth of national potential to endure modern challenges. Future discussions will be directed to the regulation of the relevant legislative dimension, to the launch of the Armenian Space Project including also the possibility of having Armenia's own artificial satellite", said the Secretary of RA Security Council Armen Grigoryan. He officially visited BAO in 2018 and had discussions with BAO Director Areg Mickaelian. The possible opportunity of having Armenia's own satellite was also discussed. The Government of Armenia has been working on legislative amendments related to Space Transport since 2018 and RA Law on Space Activities (discussed and prepared in March 2019; https://www. e-draft.am/projects/1568/about) is now ready for acceptance by the RA National Assembly.

\section{Other space related activities in Armenia}

Michael Keziryan, the Director of the International Space Safety Foundation (ISSF) visited BAO in 2018 and discussed future possible collaboration with BAO Director Areg Mickaelian. Narine Knajyan, one of NASA's administrative directors, visited BAO and delivered a seminar on the topic of "NASA's Cassini mission to Saturn" in 2017. NASA's Ambassador Elena Semerjyan visited the "AYAS" Armenian Aerospace Society in 2018, and presented NASA's future projects and plans. ARMSAT Armenian satellite project has been prepared with French partners (LATMOS, University of Versailles Saint Quentin, UVSQ). British, Belgian and Swiss scientists (PI from Armenia: Areg Mickaelian) have also participated in the process of the development of the project. The possible organization of a regional summer school on "Space Technologies" was discussed with French partners (LATMOS, UVSQ). The Space Security Project has been discussed between BAO's director Areg Mickaelian and Aram Saharian, Head of Scientific policy department of the State Committee of Science (SCS) of the Ministry of Education and Science of the RA. The Ministries of Defense and Emergency Situations, NAS RA and other governmental units are also planned to be included in the project.

"The Space Club" (now: "AYAS" Armenian Aerospace Society NGO, RA Ministry of Education and Science) was established by Avetik Grigoryan (President of "AYAS", Co-founder at Armenian Rocket Modeling Society) in 1988, where space flights and technology, or other related field courses are being taught. Avetik Grigoryan as the head of the theoretical research bureau has participated in creation of missile defense facilities for Armenia in the framework of Military-Industrial complex from 1990 to 2000. He has published a science-popular book "From the Depth of Centuries to Space" in 2013, the last two chapters of which are devoted to space flight theory, rocket engineering and space observation. The book was distributed to the schools in Armenia and Artsakh. "AYAS" has proposed to create a working group that will develop a mini-satellite (CubSat) project, will generate it, conduct its work tests and prepare for the dissemination (it is also recommended to involve university and school students) by integrating the professional resources of the Aerospace Society's and other organizations. The launch will be carried out by a foreign CubeSater orbit launching servicing company. It will become the first satellite in Armenia, which will be launched into an orbit around the Earth, as 
an easier, faster and low-price satellite. It will conduct a technological scientific experiment directed to solving the urgent problem with the space junk and consequently it will encourage the Armenian society and will bring a new prestige to Armenia.

Space museum was established on Grigor Gurzadyan's initiative on 27 June 2001 in Garni, and later on 28 Nov 2015 it was moved to Yerevan by his son Vahagn Gurzayan's efforts (http:// garni-cosmos.com). The exposition of the museum includes unique items of early space epoch created in Armenia: a genuine landing capsule returned from space, other items operated in space, replica of space observatory ORION-2 being exhibited in EXPO-2000, Hanover, other devices operated at space experiments. Also, the exhibition includes remarkable documents associated to early space research and space flights, handwritten documents by Soviet cosmonauts, designers of spacecrafts VOSTOK, SOYUZ and scientists, as well as of NASA astronaut and the designer of American spacecraft.
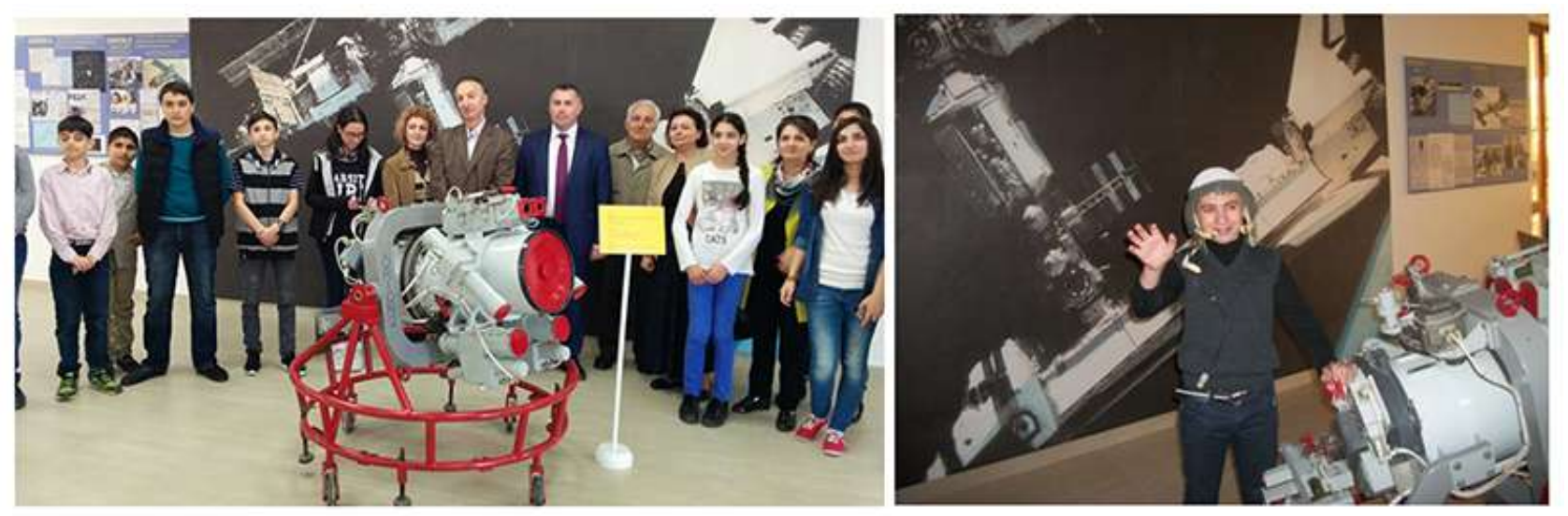

The Space Museum in Yerevan, Armenia

Armenia has started to participate in NASA's Space Apps Hackathons since 2016 (Organizer: Arman Atoyan, Head of X-Tech and ARLOOPA companies). Among the organizers, there are X-Tech, FAST (Foundation for Armenian Science and Technology), LOCATOR, BAO, and other companies.

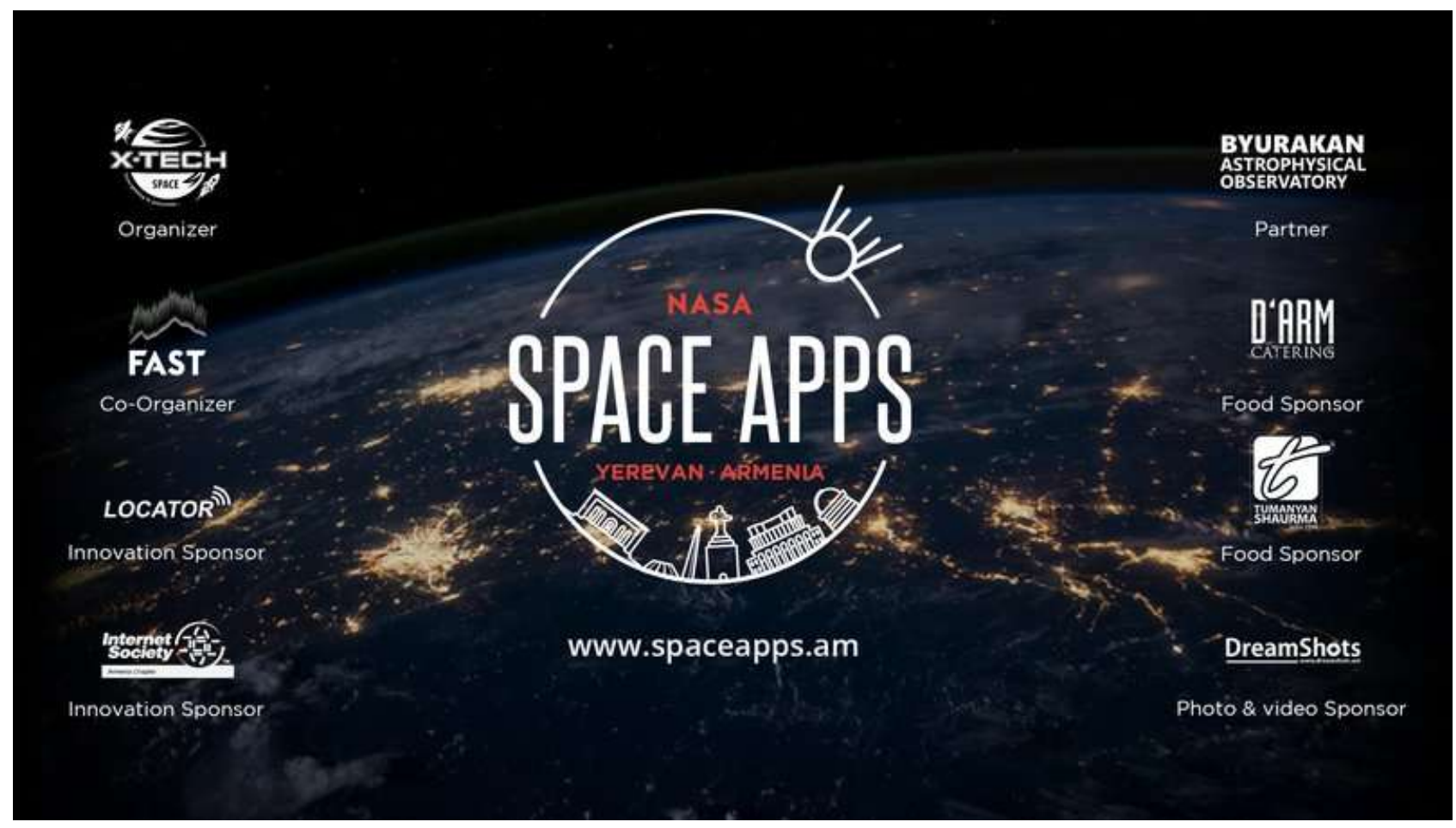

NASA Space Apps Hackathons in Armenia

An idea and design to create a "Center for Innovative Space Technology Research and Development" 
in Byurakan, attached to BAO, as well as a space station, was developed by architect student Narek Petrosyan, as a diploma thesis at the National University of Architecture and Construction of Armenia. This idea shows that the Armenian young people are eager to develop Space sciences and technologies and build a modern space-oriented society.

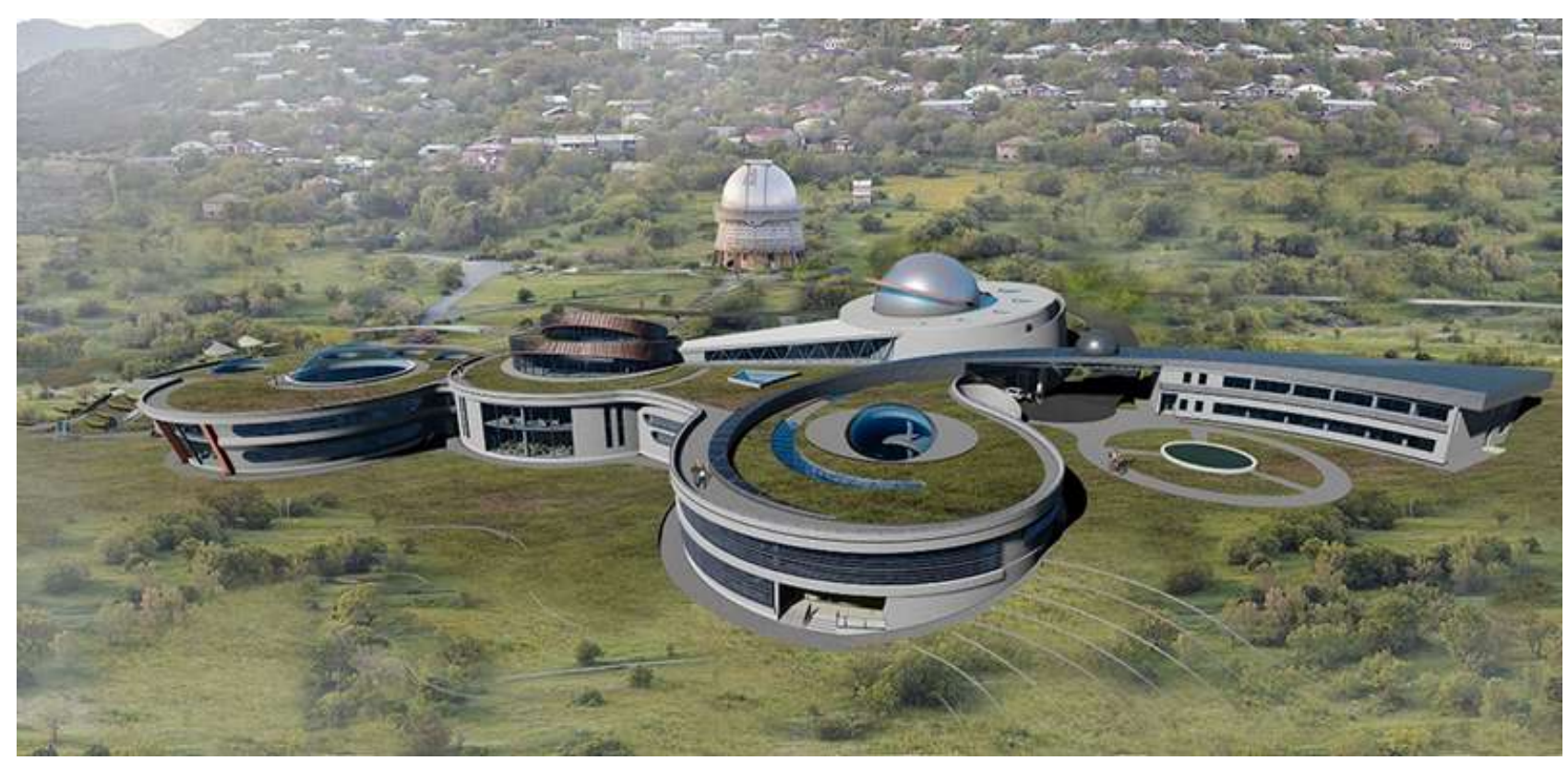

Byurakan Center for Space Technology Research and Development 


\section{References}

Berthier J., Sarkissian A., Mickaelian A., Thuillot W., 2009, Proc. European Planetary Science Congress, p. 526

Boyarchuk A. A., Gershberg R. E., Granitskij L. V., Kovtunenko V. M., Krmoyan M. N., Cruvellier P., Courtes G., Pronik V. I., Severnij A. B., Tovmassian H. M., Khojayants Y. M., Hua C. T., 1984, ARep, 10, 163

Gurzadyan G. A., 1974, Nature, 250 (5463), 204

Gurzadyan G. A., 1992, Theory of Interplanetary Flights, Moscow (in Russian)

Gurzadyan G. A., 1996, Theory of Interplanetary Flights, London, "Gordon and Breach"

Gurzadyan G. A., 2002, Space Dynamics, "Francis and Taylor"

Gurzadyan G. A., Ohanesyan J. B., 1972, Nature, 239 (5367), 90

Gurzadyan G. A., Rustambekova S. S., 1975, Nature, 254 (5498), 311

Harutyunian H. A., Mickaelian A. M., Farmanyan S. V., (Eds.) 2015, Relation of Astronomy to Other Sciences, Culture and Society, Proceedings of a Meeting held on 7-10 October 2014 in Byurakan, Armenia. Yerevan, Arm. National Acad. Sci. "Gitutyun" Publ. House, 460 p. (Arm)

Harutyunian H. A., Nikoghosyan E. H., Melikian N. D., et al. 2017, ComBAO, 64, 116

Hayes M., Östlin G., Mas-Hesse J. M., Kunth D., Leitherer C., Petrosian A., 2005, A\&A, 438, 71

Hovhannisyan L. R., Mickaelian A. M., Weedman D. W., Le Floc'h E., Houck J. R., Soifer B. T., Brand K., Dey A., Jannuzi B. T., 2009, AJ, 138, 251

Kunth D., Atek H., Östlin G., Hayes M., Mas-Hesse M., Leitherer C., Petrosian A., Schaerer D., 2010, ASSP, 15, 203

Mas-Hesse J. M., Kunth D., Atek H., Östlin G., Leitherer C., Petrosian A., Schaerer D., 2009, Ap\&SS, 320,35

Massaro E., Mickaelian A. M., Nesci R., Weedman D., 2008, The Digitized First Byurakan Survey (book)

Mickaelian A. M., 2006, RoAJ, 165, 23

Mickaelian A. M., 2007, HiA, 14, 594

Mickaelian A. M., Grigoryan A. E., 2015, RASCS Conference, p. 148

Mickaelian A. M., Sargsyan L. A., Mikayelyan G. A., Erastova L. K., Sinamian P. K., 2006, Virtual Observatory: Plate Content Digitization, Archive Mining and Image Sequence Processing, Proc. of iAstro workshop, Sofia, Bulgaria, 2005, p. 82

Mickaelian A. M., Nesci R., Rossi C., Weedman D., Cirimele G., Sargsyan L. A., Erastova L. K., Gigoyan K. S., Mikayelyan G. A., Massaro E., Gaudenzi S., Houck J., Barry D., D'Amante L., Germano P., 2007, A\&A, 464, 1177

Mickaelian A. M., Malkov O. Y., Samus N. N., (Eds.) 2012, 50 years of Cosmic Era: Real and Virtual Studies of the Sky; Proceedings of the Conference of Young Scientists of CIS Countries held on 21-25 Nov 2011 in Yerevan, Armenia. Yerevan, "EditPrint" Publishing House, 252 p. (Rus, Eng)

Mickaelian A. M., Sarkissian A., Berthier J., Meftah M., Thuillot W., Vachier F., 2019, Icarus, 330, 5

Nikoghosyan E. H., 2017, ComBAO, 64, 126 
Sagan C., 1973, Communication with Extraterrestrial Intelligence (CETI); Proc. International Conference held in Byurakan on September 6-11, 1971, Cambridge

Sargsyan L., Mickaelian A., Weedman D., Houck J., 2008, ApJ, 683, 114

Sarkissian A., Arzoumanian E., Mickaelian A. M., Berthier J., Thuillot W., Vachier F., 2012, Proc. Young Scientists Conference, p. 56

Sarkissian A., Gopala Krishna B., Crichton D. J., Beebe R., Yamamoto Y., Arviset C., Di Capria M. T., Mickaelian A. M., 2016, The International Planetary Data Alliance (IPDA): Overview of the Activities, ASPC, 505, 29S

Tovmassian H. M., 1965, Extraterrestrial Civilizations; Proc. All-Union Conference held in Byurakan on May 20-23, 1964. Publishing House of the Armenian Academy of Sciences, Yerevan, 152 p. (Rus, Eng)

Tovmassian H. M., Khojayants Y. M., Krmoyan M. N., Kashin A. L., Zakharian S. Z., Hovhannessian R. K., Mkrtchian M. A., Tovmassian G. H., Huguenin D., Bootov V. V., Romanenko Y. V., Laveikin A. I., Aleksandrov A. P., 1988, AZh, 14, 291

Tovmassian H. M., Lorenz H., Priebe A., Richter G. M., Schmidt K.-H., Khodjayants Y. M., Krmoyan M. N., Isajanian R. V., Zakharian A. Z., 1991, Astron. Nachr., 312, 281

Tovmassian H. M., Navarro S. G., Cardona O., 1996, AJ, 111, 306 